\title{
G s. \\ Immunological effect of irreversible electroporation on solid tumors
}

\section{Xiaoxia Guo}

Shanghai Jiao Tong University Medical School Affiliated Ruijin Hospital

\section{Fang Du}

Shanghai Jiao Tong University School of Medicine Affiliated Renji Hospital

\section{Qin Liu}

Shanghai Jiao Tong University Medical School Affiliated Ruijin Hospital

\section{Yan Guo}

Shanghai Jiao Tong University Medical School Affiliated Ruijin Hospital

\section{Qingbing Wang}

Shanghai Jiao Tong University Medical School Affiliated Ruijin Hospital

\section{Wei Huang}

Shanghai Jiao Tong University Medical School Affiliated Ruijin Hospital

\section{Zhongmin Wang}

Shanghai Jiao Tong University Medical School Affiliated Ruijin Hospital

\section{Xiaoyi Ding}

Shanghai Jiao Tong University Medical School Affiliated Ruijin Hospital

zhiyuan wu ( $\square$ wuzhiyuan@shsmu.edu.cn )

Shanghai Jiao Tong University Medical School Affiliated Ruijin Hospital https://orcid.org/0000-00034746-2168

\section{Research article}

Keywords: Irreversible electroporation, Hepatocellular carcinoma, Tumor ablation, Immunological effect, Antitumor immune response

Posted Date: December 7th, 2020

DOI: https://doi.org/10.21203/rs.3.rs-121118/v1

License: (c) (i) This work is licensed under a Creative Commons Attribution 4.0 International License. Read Full License 
Version of Record: A version of this preprint was published at BMC Cancer on April 21st, 2021. See the published version at https://doi.org/10.1186/s12885-021-08176-x. 


\section{Abstract \\ Background}

This study intends to investigate the immunological effects of tumor ablation with irreversible electroporation (IRE).

\section{Methods}

We evaluated the systemic immune response in patients with hepatocellular carcinoma (HCC) after IRE treatment. Furthermore, we analyzed the tumor infiltrating $T$ lymphocytes and the level of serum cytokines in IRE and control groups of tumor-bearing mice.

\section{Results}

We observed that IRE induced an increase in WBC, neutrophil and monocyte counts and a decrease in lymphocyte count 1 day post-IRE and returned to baseline values within 7 days in the patients. Meanwhile, circulating $\mathrm{CD} 4^{+} \mathrm{T}$ cell subsets, but not $\mathrm{CD} 8^{+}$, decreased 1 day post-IRE. The activated $\mathrm{T}$ cells and natural killer (NK) cells increased, and regulatory $T$ (Treg) cells decreased. Furthermore, a significant increase in cytotoxic CD8 ${ }^{+} \mathrm{T}$ cells infiltration was observed on ablative tumors in mice. The level of serum IFN- $y$ also significantly increased in the IRE group.

\section{Conclusions}

Our study demonstrated that IRE not only induced immediate innate immune response dominated by the increase of neutrophils, monocytes and NK cells, but also upregulated activated T cells and downregulated Treg. Meanwhile, the results from the animal model indicated that IRE could induce antitumor adaptive immunity dominated by cytotoxic $\mathrm{CD} 8^{+} \mathrm{T}$ cells.

\section{Background}

Image-guided tumor ablation therapies such as radiofrequency ablation, microwave ablation and cryoablation are now in widespread clinical use to treat a broad range of benign or malignant solid tumors $^{1,2}$. Most of these therapies rely on thermal energy to destroy the tumor tissues by inducing coagulation necrosis. Irreversible electroporation (IRE) is a new non-thermal tumor ablation technique that involves the application of high voltage electrical pulses across the target tissue causing the formation of permanent nanopores in the cell membranes ${ }^{3}$. Unlike conventional thermal ablation modalities, IRE induces cell death, sparing the connective tissue scaffolds, therefore, vital structures such as blood vessels or bile ducts are preserved. Additionally, its efficacy is not impaired by heat sink effects 
in the treatment of tumors located close to large blood vessels ${ }^{4,5}$. These advantages make IRE suitable to target tumors that cannot be treated by thermal ablations.

The accumulating evidence from the literature suggest that the host immune response is involved in cancer development and progression; activating antitumor immune response plays a crucial role in cancer control and therapy ${ }^{6-8}$. Since increased permeability of the cell membrane is thought to be the primary mechanism of cell death caused by $\operatorname{IRE}^{9}{ }^{9}$, the substantial native tumor antigens may be exposed, allowing for them to act as in situ vaccines to generate antitumor immune reaction ${ }^{10}$. Meanwhile, intact and persistent microvessels within the IRE ablation zone may facilitate the infiltration of immune cells ${ }^{11}$. While a few studies had reported that IRE did not induce any change in immune cell infiltration, other contradictory reports suggest that IRE provides beneficial immunological effects ${ }^{12-16}$. Although the literature on immune cell recruitment after IRE treatment remain conflicting, there is strong evidence of local and systemic antitumor immune response resulting from IRE.

Based on the contradictory results in these preclinical animal studies, we aimed to further investigate the immunological response to tumor ablation with IRE in patients with solid tumors and mouse models bearing tumors.

\section{Methods}

\section{Patients}

The Ethics Committee of Ruijin Hospital Affiliated to Shanghai Jiao Tong University School of Medicine approved this retrospective study (reference number: AF-0406). Written informed consent was obtained from each patient. From October 2016 to August 2019, 61 patients in our center underwent IRE treatment (including 26 liver tumors, 17 pancreatic tumors, 4 renal tumors, 5 adrenal gland tumors, 6 retroperitoneal tumors; one patient with both liver and pancreatic tumors, and two patients with both liver and retroperitoneal tumors). Due to the immunity of these types of patients were relative to the types of malignancies that were treated were highly variable, we selected a single tumor type-- hepatocellular carcinoma (HCC) for immunological analysis. A total of 11 patients with HCC (8 men, 3 women, mean age, $60.8 \pm 9.3$ years) were enrolled in the study. All patients had a history of chronic HBV infection and cirrhosis. No chemotherapy or interferon therapy was received previously. After the diagnosis of HCC, all patients were treated with oral nucleoside antiviral drugs. During the follow up, all patients received no adjunctive therapies.

\section{IRE procedure in patients and sample collection}

Two experienced interventional radiologists performed all the procedures. All patients were administered with muscle relaxants and general anesthesia. IRE was performed using a NanoKnife system (AngioDynamics, Latham, NY, USA) with an electrocardiogram (ECG) synchronization device under the guidance of CT. Nineteen gauge monopolar needles were placed in parallel around the tumors 
percutaneously at the intervals of 1.2-2.2 cm. Tip exposure of the needles was $1.0-2.0 \mathrm{~cm}$. The number of needles was decided according to the tumor size. The parameters of IRE ablation were set as follows: average electric field intensity, $1500 \mathrm{~V} / \mathrm{cm}$; pulse length, 70-90 $\mu \mathrm{s} ; 90$ pulses. The ablation range covered the whole tumor with an ablation margin of at least $5 \mathrm{~mm}$. Peripheral blood samples were collected 1 day before IRE therapy and used as baseline values. Additional blood samples were collected 1 day, 3 days, 7 days, 2 weeks, and 4 weeks after IRE treatment. Blood tests included blood cells analysis and immune cells analysis. A routine clinical flow cytometry test protocol was followed for analyzing immune cells in the peripheral blood.

\section{Cell culture and animal models}

All animal experiments were conducted by the Guidelines for the Care and Use of Laboratory Animals of Shanghai Jiao Tong University School of Medicine. The mouse hepatic carcinoma cell lines, $\mathrm{H} 22$ were purchased from China Center for Type Culture Collection (Wuhan, China). H22 cells were cultured in RPMI containing $10 \%$ FBS and $1 \%$ penicillin-streptomycin, in an incubator with a humidified atmosphere of $5 \%$ $\mathrm{CO}_{2}$ at a temperature of $37^{\circ} \mathrm{C}$. $\mathrm{H} 22$ cells $\left(5 \times 10^{6}\right)$ were suspended in $200 \mu \mathrm{L}$ phosphate buffered saline and injected subcutaneously into the right flank of 5- to 6-week-old male BALB/c mice (commercially obtained from LINGCHANG BIOTECH, Shanghai, China). Two weeks after the injection, the diameter of the tumors reached nearly $1 \mathrm{~cm}$.

\section{IRE procedure in mice and sample collection}

After two weeks of modeling, a total of 30 mice were randomly divided into two groups: the control group $(n=15)$ and the IRE group $(n=15)$. For the IRE group, the mice were anesthetized by injecting sodium pentobarbital ( $10 \mathrm{mg} / \mathrm{mL}, 50 \mathrm{mg} / \mathrm{kg}$ body weight) intraperitoneally. Then, each mouse was fixed on an insulating plate, and the IRE procedure was performed using an ECM 830 Square Wave Electroporation system (BTX Harvard Apparatus, Holliston, MA, USA) with a pair of genetrodes (BTX item \#45-0161, BTX Harvard Apparatus, Holliston, MA, USA). The genetrodes with a $10 \mathrm{~mm}$ gap were inserted into the tumors to deliver electric pulses with the following parameters: voltage, $1200 \mathrm{~V}$; pulse length, $90 \mu \mathrm{s} ; 90$ pulses. This protocol was selected to produce a complete ablation for the tumors. The mice in the control group received sham procedures with the genetrodes inserted into the tumors but no electric pulses were given. The blood samples and tumor samples were collected at 3, 7, and 14 days post-IRE procedure from five mice separately. Samples from the control group were collected at the same time. At the end of the experiments, the mice were killed by standard $\mathrm{CO}_{2}$ asphyxiation.

\section{Flow cytometry analysis}

Tumors isolated from the mice were digested mechanically to obtain single-cell suspensions. The cell suspensions were surface stained with PE-Cy7-labeled anti-CD3 (eBioscience, San Diego, CA, USA), FITClabeled anti-CD4 (eBioscience, San Diego, CA, USA) and PE-Cy5-labeled anti-CD8 (eBioscience, San Diego, CA, USA) monoclonal antibodies, and then treated with Fixation/Permeabilization Kit (BD Biosciences, Franklin Lakes, NJ, USA). Then, the cells were stained intracellularly with PE-labeled anti-FoxP3 
(eBioscience, San Diego, CA, USA) and Pacific Blue-labeled anti-Granzyme B monoclonal antibodies (Biolegend, San Diego, CA, USA). The stained cells were analyzed with CytoFLEX LX flow cytometer (Beckman Coulter, Brea, CA, USA). Data were analyzed using CytExpert software (Beckman Coulter, Brea, CA, USA).

\section{Lactate dehydrogenase (LDH) cytotoxicity assay}

Single-cell suspensions from mice tumors were prepared. T cells were isolated from the single-cell suspensions by negative selection using the Pan T Cell Isolation Kit II (Miltenyi Biotec, Bergisch Gladbach, Germany). The isolated T cells were stimulated with recombinant murine IL-2 (PeproTech, Rocky Hill, NJ, USA) for 3 days. Then, the T cells were added to $\mathrm{H} 22$ cells with an effector to target cell ratio of 20:1, and the cells were co-cultured in 96-well plates for $24 \mathrm{~h}$. Evaluation of $\mathrm{T}$ cell cytotoxicity activity was

performed using an LDH-Cytox ${ }^{\mathrm{TM}}$ Assay kit (BioLegend, San Diego, CA, USA), according to the manufacturer's protocol. The cytotoxicity percentage was calculated as follows: (LDH experimental LDH spontaneous) / (LDH maximum - LDH spontaneous) $\times 100 \%$. LDH experimental represents the LDH release activity from the T cells and tumor cells co-culture. Spontaneous LDH release activity was obtained from tumor cells cultured separately. The maximal LDH release activity was obtained following lysis of the tumor cells.

\section{Immunohistochemistry analysis}

The tumor tissue removed from each mouse was fixed in $4 \%$ paraformaldehyde and embedded in paraffin for $5 \mu \mathrm{m}$-thick sections. After being deparaffinized and rehydrated, the sections were treated with sodium citrate buffer $(\mathrm{pH}=6)$, and the microwave was used for antigen retrieval. The activity of endogenous peroxidase was blocked with $3 \% \mathrm{H}_{2} \mathrm{O}_{2}$ in methanol. The sections were then incubated with anti-CD3 monoclonal antibody (Abcam, Cambridge, UK), anti-CD4 monoclonal antibody (Abcam, Cambridge, UK), and anti-CD8 monoclonal antibody (Abcam, Cambridge, UK) at $4^{\circ} \mathrm{C}$ overnight, respectively. Afterwards, the sections were stained with HPR-conjugated secondary antibody, and the positive reactions were visualized with diaminobenzidine (DAB). Finally, the sections were counterstained with Mayer's hematoxylin. Digital images of the stained sections were obtained in five randomly selected fields both at the interior regions and the margin of tumors using a fluorescence microscope. The positive cell numbers were counted and the results from the five areas were averaged and used in the statistical analysis.

\section{Cytometric bead array (CBA) analysis}

Blood serum was separated from the blood sample obtained from the tumor-bearing mouse by centrifugation at $3000 \mathrm{~g}$ for $20 \mathrm{~min}$ and then stored at $-80^{\circ} \mathrm{C}$, until later analysis. Serum cytokine analysis was performed using the CBA Flex Set (BD Biosciences, Franklin Lakes, NJ, USA), containing mouse IFNY, IL-1 $\beta$, IL-2, IL-10, and TNF-a. Mouse Soluble Protein Flex Set Standards and samples were prepared according to the manufacturer's instruction. The samples were acquired on the flow cytometer (BD 
LSRFortessaTM X-20, Franklin Lakes, NJ, USA). The data were analyzed using FCAP Array software (BD Biosciences, Franklin Lakes, NJ, USA).

\section{RNA sequencing analysis}

Tumors from IRE and control groups 7 days postoperative were separated for RNA sequencing analysis. Total RNA was extracted using Trizol reagent (Roche, Basel, Switzerland). Total RNA quality was evaluated on an Agilent 2100 Bioanalyzer (Agilent, Santa Clara, CA, USA). Library preparation was performed from the pooled RNA using an Illumina TruSeq RNA Sample Preparation Kit v2 (Illumina, San Diego, CA, USA) and sequenced on the Illumina HiSeq 4000 platform (Illumina, San Diego, CA, USA). The sequenced reads were aligned to the mouse genome mm10 by HISAT2 ${ }^{17}$. FeatureCounts was used to quantitate the transcriptome, using the GTF annotation files ${ }^{18}$. Differential analyses were performed to the count files using DESeq2 packages, following standard normalization procedures ${ }^{19}$. The differentially expressed genes (DEGs) were identified with $p$ values $<0.05$ and absolute log2 fold change $>1$. Gene Ontology (GO) enrichment analysis was performed using Metascape (http://metascape.org).

\section{Statistical analysis}

Statistical analysis was performed using SPSS statistical software, version 23 (IBM, Armonk, NY, USA). The immunohistochemistry results were analyzed with the Mann-Whitney test. For other analysis, Student's $t$-test was used. All data were expressed as mean \pm SEM (standard error of the mean) of $n$ independent measurements. GraphPad Prism 7 software (GraphPad, San Diego, CA, USA) was used to plot graphs. $P<0.05$ was considered statistically significant.

\section{Results}

\section{An immediate innate immune response was observed after IRE}

Peripheral blood samples obtained from 11 patients with HCC at six different time points, pre- and postIRE ablation, were tested for systemic immune reaction. However, complete follow-up information was not obtained from some patients. We applied scatter plots to show the detailed information collected. As shown in Fig. 1, WBC, neutrophil and monocyte counts, as well as neutrophil to lymphocyte ratio (NLR) were found to be elevated significantly 1 day post-IRE; however, they returned to baseline values gradually within 7 days after IRE. On the contrary, lymphocyte count declined 1 day post-IRE, which then increased gradually. Meanwhile, IRE led to a slight and non-significant increase on the percentage of natural killer (NK) cells $\left(\mathrm{CD} 56^{+} \mathrm{CD} 16^{+}\right)$on day $1(11.4 \pm 8.5$ vs $15.9 \pm 9.7 \%)$, followed by a decrease on day 3 , then a significant increase was observed from day 3 to day $14(10.4 \pm 6.4$ vs $15.3 \pm 8.2 \%, p<0.05)$ (Fig. $1 F)$.

\section{IRE led to increased activated T cells and decreased Treg cells}


The lymphocytes profile data from all the patients were analyzed, the results showed that compared to baseline levels, the percentages of $\mathrm{CD}^{+}{ }^{+}$(Fig. 2A) and $\mathrm{CD}^{+}{ }^{+} \mathrm{CD} 4^{+}$(Fig. 2B) T cells were decreased immediately after IRE (day 1 ), followed by a steady increase in the next days, as did the activated (CD4 ${ }^{+}$ $\left.\mathrm{CD}^{2} 8^{+}\right)$(Fig. 2E) and memory $\left(\mathrm{CD} 4^{+} \mathrm{CD}^{2} 5 \mathrm{RO}^{+}\right)($Fig. $2 \mathrm{H}) \mathrm{CD} 4^{+} \mathrm{T}$ cells. Meanwhile, the patients showed a steady increase in the percentage of $C D 4^{+}$naïve cells $\left(C D 4^{+} C D 45 R A^{+}\right)$(Fig. 2G). However, the percentages of $\mathrm{CD}^{+} \mathrm{CD}^{+} \mathrm{T}$ cells (Fig. $\left.2 \mathrm{C}\right)$, as well as its activated subset $\left(\mathrm{CD} 8^{+} \mathrm{CD} 28^{+}\right)(\mathrm{Fig} .2 \mathrm{~F})$ remained unchanged. Moreover, the percentage of activated T cells $\left(\mathrm{CD}^{+} \mathrm{CD} 69^{+}\right)$increased significantly 3 days post-IRE $(1.6 \pm 0.5$ vs $7.7 \pm 3.0 \%, p<0.01)$, followed by a decrease on day 7 (Fig. 2D). The trend for regulatory $\mathrm{T}$ (Treg) cells $\left(\mathrm{CD} 4^{+} \mathrm{CD} 25^{+} \mathrm{CD} 127^{\text {low }}\right)$ was similar to activated $\mathrm{T}$ cells at the beginning, a decrease was observed from day 3 to day $14(2.1 \pm 0.8$ vs $1.3 \pm 0.8 \%)$, but a significant increase was induced 1 month after IRE (1.1 \pm 0.7 vs $3.0 \pm 0.8 \%, p<0.01)$ (Fig. 2I).

\section{Cytotoxic CD ${ }^{+} \mathrm{T}$ cells increased but Treg decreased in mice tumor after IRE}

To probe whether the IRE treatment resulted in significant up-regulation of pathways associated with the adaptive immune process, RNA-seq expression was performed in IRE treated mice and controls. The results of GO analysis indicated that several adaptive immune process related pathways were upregulated in the IRE treatment group, including antigen processing and presentation of exogenous peptide antigen, antigen processing-cross presentation, and adaptive immune response (Fig. 3A, B). Additionally, several pathways, such as signaling by TGF-beta Receptor Complex were down-regulated in IRE treatment group (Fig. 3C, D).

The results of flow cytometry analysis revealed that $\mathrm{CD} 4^{+} \mathrm{T}$ lymphocytes increased in the IRE group on day 7 and day 14, and CD8 ${ }^{+}$T lymphocytes increased on day 3 and day 14 (Fig. 4A-C). We observed significantly lower Treg cells $\left(C D 4^{+}\right.$FoxP $\left.^{+}\right)(26.9 \pm 25.9$ vs $88.5 \pm 9.4 \%, p<0.01)$ on day 3 (Fig. 4D, E) and remarkably higher cytotoxic $\mathrm{CD}^{+} \mathrm{T}$ cells $\left(\mathrm{CD} 8^{+}\right.$Granzyme $\left.\mathrm{B}^{+}\right)(7.1 \pm 2.3$ vs $3.2 \pm 1.6 \%, \mathrm{p}<0.05)$ on day 7 (Fig. 4F, G) in the IRE group than those in the control group.

Gene expression profiling also revealed a significant increase in T cell mediated cytotoxicity associated genes (Gzmb) in the tumor post-IRE treatment (Fig. 5A), which was consistent with the results of flow cytometry analysis (Fig. 4F, G). To further confirm whether IRE treatment induced specific antitumor immunity, we analyzed cytotoxic activity of $T$ lymphocytes. Antitumor cytotoxicity activity of $T$ cells treated with IRE was higher than that of the control group $(97.8 \pm 1.2$ vs $66.0 \pm 3.9 \%, p<0.001)$ on day 3 (Fig. 5B). All above results confirmed specific antitumor immunity induced by IRE.

\section{$\mathrm{CD}^{+} \mathrm{T}$ cells infiltrated predominantly at margins but $\mathrm{CD} 4^{+} \mathrm{T}$ cells also infiltrated into the mice tumor after IRE}

The immunohistochemistry results revealed that while the infiltration of $\mathrm{CD}^{+}$(Fig. 6A, B) and $\mathrm{CD} 4^{+} \mathrm{T}$ lymphocytes (Fig. 6C, D) was intense at the margin, they were also found in the center of tumors. In the IRE group, the number of $\mathrm{CD}^{+} \mathrm{T}$ lymphocytes significantly higher than the control group on day 3 (3.1 \pm 
2.5 vs $2.1 \pm 1.0, p<0.01)$ and day $14(6.9 \pm 6.0$ vs $3.0 \pm 1.8, p<0.001)$ in the center of tumors, and CD $4^{+} T$ lymphocytes on day $7(1.9 \pm 1.0$ vs $0.9 \pm 0.4, p<0.001)$ and day $14(1.8 \pm 1.2$ vs $1.0 \pm 0.6, p<0.05)$. However, we only found infiltration of $\mathrm{CD} 8^{+} \mathrm{T}$ lymphocytes (Fig. 6E, F) at the margins, but scarcely in the center. Although it did not reach a statistically significant level, we did find that in IRE group, there were higher numbers of infiltrating $\mathrm{CD}^{+} \mathrm{T}$ lymphocytes in the margin of tumors at different time points compared to the control group ( $10.3 \pm 5.7$ vs $4.9 \pm 3.9 ; 7.6 \pm 6.0$ vs $6.8 \pm 6.3 ; 10.0 \pm 7.0$ vs $8.0 \pm 6.4$, respectively).

\section{IFN-y increased in the serum of tumor bearing mice after IRE}

Furthermore, we observed a significant increase in the expression profiles associated with cytokine production, predominantly IFN-y-mediated signaling pathway. Tumor-bearing mice in the IRE group also showed significantly higher serum level of IFN-Y (Fig. 7A) on both day 7 and 14, in comparison with the control group ( $2.0 \pm 0.7$ vs $0.8 \pm 0.7, p<0.05 ; 1.1 \pm 0.6$ vs $0.1 \pm 0.1, p<0.05$, respectively). Although not statistically significant, we found that the serum levels of IL-2, TNF-a, and IL-1 $\beta$ in the mice treated with IRE were higher than the levels in the control group (Fig. 7B-D). The elevated levels of these would help increase anti-tumor immunity in the body. In addition, the IL-10 level in the IRE group decreased at all time points after IRE treatment (Fig. 7E).

\section{Discussion}

IRE is a novel, non-thermal ablation modality, which was used to treat tumors. Unlike with surgical resection, the ablated tumor tissues are not removed, apoptotic or necrotic cells release damageassociated molecular patterns, such as HMGB1, ATP, ROS and calreticulin, which may serve to achieve in situ tumor vaccination ${ }^{20}$. As a result, antitumor immune response may be induced that in turn can effectuate regression of distant and metastatic lesions, increase the efficacy of IRE. In this study, we investigated the immunological response post-ablation of IRE in patients with $\mathrm{HCC}$, as well as in mice bearing tumors, to provide more evidence for clinical tumor treatment.

First, we tested whether IRE induced a systemic immunological response in patients with HCC. Shortly after IRE treatment, an increase in WBC, neutrophil and monocyte counts were observed in the peripheral blood. Neutrophils are the predominant circulating leukocyte population and constitute an important part of the innate immunity. Several studies have demonstrated various antitumor effects of neutrophils, including direct cytotoxicity and antibody-dependent cell-mediated cytotoxicity (ADCC) ${ }^{21,22}$. Recent reports also suggest neutrophils display antimetastatic properties, which were mostly attributed to circulating neutrophils ${ }^{23,24}$. Moreover, neutrophils could secrete cytokines and chemokines activating other immune cells ${ }^{25}$. Bulvik et al. compared the effects of IRE with those of RFA and found persistent patency of vascular within the ablation area from IRE increased the infiltration of immune cells and induced more robust systemic effects ${ }^{11}$. In a more recent report Sugimoto et al. found a significant early increase in macrophage migration inhibitory factor, followed by rapidly mobilizing of monocytes from the peripheral blood to the ablation zone after IRE, but not RFA, which may facilitate the early reparative 
process and result in shrinkage of ablation zone ${ }^{26}$. As another key effector of the first-line defense against tumors, NK cells were also found to be elevated post-IRE. Similar to neutrophils, NK cells kill tumor cells through the cytotoxic activity without any specific antigen stimulation; they can also regulate innate and adaptive immunity by secreting cytokines and chemokines ${ }^{27}$. The major cytokine produced by NK cells is IFN- $\gamma$, which mediates the induction of Thelper 1 (Th1) cells, which are associated with a good prognosis of patients with cancer ${ }^{28}$. Indeed, we did found that IFN- $y$ increased in the serum of mice bearing tumors after IRE. Our results showed that IRE indeed could induce an immediate innate immune response characterized by the increase of neutrophils, monocytes and NK in patients, which may help the patients to reconstruct anti-tumor immunity.

Increasing evidence shows that elevated NLR is a prognostic indicator of mortality 29,30 . In our patient study, although NLR was found to be elevated significantly 1 day post-IRE, it recovered to the base level within 1 week. This transient elevation may represent a relative lymphocytopenia, capacity of NLR to decline for a short period, reflecting host immunomodulatory activity. Indeed, we observed that IRE caused short-term depletion of circulating $\mathrm{CD} 4^{+} \mathrm{T}$ lymphocytes (activated and memory subsets), but not $\mathrm{CD}^{+} \mathrm{T}$ cells. Lymphopenia has been explored in patients with cancer undergoing chemoradiotherapy ${ }^{31}$, 32. Some reports have shown that immune reconstruction following lymphopenia shifts $T$ subsets toward a predominance of activated T cells, enhancing antitumor immunity ${ }^{33}$. Another explanation is the depletion of Treg cells, which are produced in the thymus or induced in the periphery from naïve T cells ${ }^{34}$. Pandit et al. compared the magnitude of decreased Treg cells and the highest longitudinal changes were observed early post-IRE procedure (day 3-5) compared with surgical resection ${ }^{35}$. Chaobin He et al. found a similar changes of Treg cells which increased at day 3 and decreased at intervals of day 3-7 post-IRE 36 . Furthermore, Scheffer et al. detected the levels of Treg cells at delayed time ( 2 weeks) post-IRE treatment, and a significant decrease was also found ${ }^{37}$. With a longer follow-up time in our study, similar findings showed a transitory increase of Tregs by 3 days followed by a decrease until two weeks post-IRE, accompanied by a remarkable increase of activated T cells; after 1 month Treg cells appear to be recovering, which increased significantly. Above results indicated the immunomodulatory effect of IRE with decreased immunosuppressive Treg cells and expansion of effective T cells.

Apart from systemic antitumor immunity, tumor-infiltrating lymphocytes are associated with favorable prognostic effect ${ }^{38,39}$. Especially, the introduction of immunoscore has gained significance for the classification of cancers and aid in predicting the outcomes of treatments ${ }^{40,41}$. Our tumor model study revealed that IRE treatment induced adaptive antitumor immunity within the ablative tumors, dominated by increase in cytotoxic $\mathrm{CD} 8^{+} \mathrm{T}$ cells and reduced Treg cells. It is well known that cytotoxic $\mathrm{CD} 8^{+} \mathrm{T}$ lymphocytes are crucial components of tumor-specific cellular adaptive immunity, and they produce perforin, granzyme, or TNF, IFN-y to kill tumor cells or induce apoptosis ${ }^{42,43}$. Consistently, serum cytokines, predominantly IFN- $\gamma$, were found to be increased post-IRE. However, CD ${ }^{+} \mathrm{T}$ cells infiltrated merely the margin of tumors in both IRE and control groups, which is because immune cells already inside the tumor are probably destroyed by IRE pulses, whereas, $\mathrm{CD} 4^{+} \mathrm{T}$ cells infiltrated both in the center 
and margin of the same tumor. This difference could be contributed by regional heterogeneity of tumor architecture and tumor antigens. The combined data of our systemic and local antitumor immunity induced by IRE proposed an ideal treatment window for immunotherapy by increasing the effective $T$ cells and decreasing Tregs, resulting in control recurrence and metastasis of ablation therapy. Recent literature reported that IRE combined with immune checkpoint blockade enhanced antitumor immune response, and help overcome the immunosuppressive tumor microenvironment of pancreatic cancer 44 , 45 . Therefore, IRE may be an effective modality to overcome the immunosuppressive "cold" tumor microenvironment. More studies are needed in the future to evaluate this role in other tumors such as HCC.

\section{Conclusions}

In conclusion, in the current study, we preliminarily investigated the immune activity caused by tumor ablation with IRE in both patients with HCC and tumor-bearing mice. The results demonstrated that IRE not only induced immediate innate immune response dominated by the increase of neutrophils, monocytes and NK but also upregulated activated T cells and downregulated Treg, which are a benefit for enhancing the sustained anti-tumor activity of patients. Meanwhile, the results from the animal model indicated that IRE could rapidly inhibit local tumor growth by inducing the infiltration of $\mathrm{CD} 4^{+}$and $\mathrm{CD} 8^{+} \mathrm{T}$ cells, predominantly cytotoxic $\mathrm{CD} 8^{+} \mathrm{T}$ cells. However, further investigations are needed to ascertain the long-term antitumor immunity and to evaluate how these immune responses impact the prognosis of patients with various cancer phenotypes. Moreover, the immune mechanism induced by IRE needs more in-depth studies. Furthermore, an optimal combination therapy requires validation in animal and patients, such as IRE combined with immune checkpoint inhibitors, which may improve the prognosis of patients.

\section{Abbreviations}

ADCC

antibody-dependent cell-mediated cytotoxicity

CBA

cytometric bead array

DAB

diaminobenzidine

DEGs

differentially expressed genes

ECG

electrocardiogram

GO

gene ontology

$\mathrm{HCC}$

hepatocellular carcinoma 
IRE

irreversible electroporation

$\mathrm{LDH}$

lactate dehydrogenase

NK

natural killer

NLR

neutrophil to lymphocyte ratio

Treg

regulatory $\mathrm{T}$

Th1

T helper 1

\section{Declarations}

\section{Ethical approval and consent to participate}

Human studies were approved by the Ethics Committee of Ruijin Hospital Affiliated to Shanghai Jiao Tong University School of Medicine (reference number: AF-0406) and performed in accordance with the Declaration of Helsinki. Written informed consent was obtained from all participants. Animal experiments were conducted by the Guidelines for the Care and Use of Laboratory Animals of Shanghai Jiao Tong University School of Medicine.

\section{Consent for publication}

Not applicable.

\section{Availability of data and materials}

The datasets used and/or analyzed during the current study are available from the corresponding author on reasonable request.

\section{Competing interests}

The authors declare that they have no competing interests.

\section{Funding}

This work was funded by Shanghai Municipal Key Clinical Specialty (No. shslczdzk06002). The funding body had no role in the design of the study and collection, analysis, and interpretation of data and in writing the manuscript.

\section{Author's contributions}


X.Y.D. and Z.Y.W. designed the study, X.X.G., F.D. and Y.G. performed animal experiments, Q.L. and Q.B.W. planned data collection from patients, W.H., Z.M.W., X.Y.D. and Z.Y.W. performed IRE on patients, X.X.G. drafted the paper, and Z.Y.W. revised the paper.

\section{Acknowledgements}

The authors thank Ningli Li of Shanghai Institute of Immunology \& Department of Immunology and Microbiology in Shanghai Jiao Tong University School of Medicine for her assistance in this study.

\section{References}

1. Venkatesan AM, Wood BJ, Gervais DA. Percutaneous ablation in the kidney. Radiology. 2011; 261: 375-391.

2. Mahnken $\mathrm{AH}$, Pereira $\mathrm{PL}$, de Baere $\mathrm{T}$. Interventional oncologic approaches to liver metastases. Radiology. 2013; 266: 407-430.

3. Davalos RV, Mir LM, Rubinsky B. Tissue ablation with irreversible electroporation. Annals of Biomedical Engineering. 2005; 33: 223-231.

4. Sutter O, Calvo J, N'Kontchou G, Nault JC, Ourabia R, Nahon P, et al. Safety and Efficacy of Irreversible Electroporation for the Treatment of Hepatocellular Carcinoma Not Amenable to Thermal Ablation Techniques: A Retrospective Single-Center Case Series. Radiology. 2017; 284: 877-886.

5. Distelmaier M, Barabasch A, Heil P, Kraemer NA, Isfort P, Keil S, et al. Midterm Safety and Efficacy of Irreversible Electroporation of Malignant Liver Tumors Located Close to Major Portal or Hepatic Veins. Radiology. 2017; 285: 1023-1031.

6. Vesely MD, Kershaw MH, Schreiber RD, Smyth MJ. Natural innate and adaptive immunity to cancer. Annu Rev Immunol. 2011; 29: 235-271.

7. Whiteside TL. Immune responses to malignancies. J Allergy Clin Immunol. 2010; 125: S272-283.

8. Whiteside TL. Immune suppression in cancer: effects on immune cells, mechanisms and future therapeutic intervention. Semin Cancer Biol. 2006; 16: 3-15.

9. Deipolyi AR, Golberg A, Yarmush ML, Arellano RS, Oklu R. Irreversible electroporation: evolution of a laboratory technique in interventional oncology. Diagn Interv Radiol. 2014; 20: 147-154.

10. Blankenstein T, Coulie PG, Gilboa E, Jaffee EM. The determinants of tumour immunogenicity. Nat Rev Cancer. 2012; 12: 307-313.

11. Bulvik BE, Rozenblum N, Gourevich S, Ahmed M, Andriyanov AV, Galun E, et al. Irreversible Electroporation versus Radiofrequency Ablation: A Comparison of Local and Systemic Effects in a Small-Animal Model. Radiology. 2016; 280: 413-424.

12. Al-Sakere B, Bernat C, Andre F, Connault E, Opolon P, Davalos RV, et al. A study of the immunological response to tumor ablation with irreversible electroporation. Technol Cancer Res Treat. 2007; 6: 301306. 
13. Chen X, Ren Z, Yin S, Xu Y, Guo D, Xie H, et al. The local liver ablation with pulsed electric field stimulate systemic immune reaction against hepatocellular carcinoma ( $\mathrm{HCC})$ with time-dependent cytokine profile. Cytokine. 2017; 93: 44-50.

14. Goswami I, Coutermarsh-Ott S, Morrison RG, Allen IC, Davalos RV, Verbridge SS, et al. Irreversible electroporation inhibits pro-cancer inflammatory signaling in triple negative breast cancer cells. Bioelectrochemistry. 2017; 113: 42-50.

15. Li X, Xu K, Li W, Qiu X, Ma B, Fan Q, et al. Immunologic response to tumor ablation with irreversible electroporation. PLoS One. 2012; 7: e48749.

16. Neal RE, 2nd, Rossmeisl JH, Jr., Robertson JL, Arena CB, Davis EM, Singh RN, et al. Improved local and systemic anti-tumor efficacy for irreversible electroporation in immunocompetent versus immunodeficient mice. PLoS One. 2013; 8: e64559.

17. Pertea M, Kim D, Pertea GM, Leek JT, Salzberg SL. Transcript-level expression analysis of RNA-seq experiments with HISAT, StringTie and Ballgown. Nat Protoc. 2016; 11: 1650-1667.

18. Liao Y, Smyth GK, Shi W. featureCounts: an efficient general purpose program for assigning sequence reads to genomic features. Bioinformatics. 2014; 30: 923-930.

19. Love MI, Huber W, Anders S. Moderated estimation of fold change and dispersion for RNA-seq data with DESeq2. Genome Biol. 2014; 15: 550.

20. Ringel-Scaia VM, Beitel-White N, Lorenzo MF, Brock RM, Huie KE, Coutermarsh-Ott S, et al. Highfrequency irreversible electroporation is an effective tumor ablation strategy that induces immunologic cell death and promotes systemic anti-tumor immunity. EBioMedicine. 2019; 44: 112125.

21. Elsasser D, Valerius T, Repp R, Weiner GJ, Deo Y, Kalden JR, et al. HLA class II as potential target antigen on malignant $B$ cells for therapy with bispecific antibodies in combination with granulocyte colony-stimulating factor. Blood. 1996; 87: 3803-3812.

22. Gerrard TL, Cohen DJ, Kaplan AM. Human neutrophil-mediated cytotoxicity to tumor cells. J Natl Cancer Inst. 1981; 66: 483-488.

23. Granot Z, Henke E, Comen EA, King TA, Norton L, Benezra R. Tumor entrained neutrophils inhibit seeding in the premetastatic lung. Cancer Cell. 2011; 20: 300-314.

24. Lopez-Lago MA, Posner S, Thodima VJ, Molina AM, Motzer RJ, Chaganti RS. Neutrophil chemokines secreted by tumor cells mount a lung antimetastatic response during renal cell carcinoma progression. Oncogene. 2013; 32: 1752-1760.

25. Amulic B, Cazalet C, Hayes GL, Metzler KD, Zychlinsky A. Neutrophil function: from mechanisms to disease. Annu Rev Immunol. 2012; 30: 459-489.

26. Sugimoto K, Kakimi K, Takeuchi H, Fujieda N, Saito K, Sato E, et al. Irreversible Electroporation versus Radiofrequency Ablation: Comparison of Systemic Immune Responses in Patients with Hepatocellular Carcinoma. J Vasc Interv Radiol. 2019; 30: 845-853 e846.

27. Vivier E, Raulet DH, Moretta A, Caligiuri MA, Zitvogel L, Lanier LL, et al. Innate or adaptive immunity? The example of natural killer cells. Science. 2011; 331: 44-49. 
28. Tosolini M, Kirilovsky A, Mlecnik B, Fredriksen T, Mauger S, Bindea G, et al. Clinical impact of different classes of infiltrating $T$ cytotoxic and helper cells (Th1, th2, treg, th17) in patients with colorectal cancer. Cancer Res. 2011; 71: 1263-1271.

29. Chen TM, Lin CC, Huang PT, Wen CF. Neutrophil-to-lymphocyte ratio associated with mortality in early hepatocellular carcinoma patients after radiofrequency ablation. J Gastroenterol Hepatol. 2012; 27: 553-561.

30. Suh KJ, Kim SH, Kim YJ, Kim M, Keam B, Kim TM, et al. Post-treatment neutrophil-to-lymphocyte ratio at week 6 is prognostic in patients with advanced non-small cell lung cancers treated with anti-PD-1 antibody. Cancer Immunol Immunother. 2018; 67: 459-470.

31. Grossman SA, Ellsworth S, Campian J, Wild AT, Herman JM, Laheru D, et al. Survival in Patients With Severe Lymphopenia Following Treatment With Radiation and Chemotherapy for Newly Diagnosed Solid Tumors. J Natl Compr Canc Netw. 2015; 13: 1225-1231.

32. Verma R, Foster RE, Horgan K, Mounsey K, Nixon H, Smalle N, et al. Lymphocyte depletion and repopulation after chemotherapy for primary breast cancer. Breast Cancer Res. 2016; 18: 10.

33. Williams KM, Hakim FT, Gress RE. T cell immune reconstitution following lymphodepletion. Semin Immunol. 2007; 19: 318-330.

34. Bluestone JA, Abbas AK. Natural versus adaptive regulatory T cells. Nat Rev Immunol. 2003; 3: 253257.

35. Pandit H, Hong YK, Li Y, Rostas J, Pulliam Z, Li SP, et al. Evaluating the Regulatory Immunomodulation Effect of Irreversible Electroporation (IRE) in Pancreatic Adenocarcinoma. Ann Surg Oncol. 2019; 26: 800-806.

36. He C, Wang J, Sun S, Zhang Y, Li S. Immunomodulatory Effect after Irreversible Electroporation in Patients with Locally Advanced Pancreatic Cancer. J Oncol. 2019; 2019: 9346017.

37. Scheffer HJ, Stam AGM, Geboers B, Vroomen L, Ruarus A, de Bruijn B, et al. Irreversible electroporation of locally advanced pancreatic cancer transiently alleviates immune suppression and creates a window for antitumor T cell activation. Oncoimmunology. 2019; 8: 1652532.

38. Fridman WH, Pages F, Sautes-Fridman C, Galon J. The immune contexture in human tumours: impact on clinical outcome. Nat Rev Cancer. 2012; 12: 298-306.

39. Galon J, Costes A, Sanchez-Cabo F, Kirilovsky A, Mlecnik B, Lagorce-Pages C, et al. Type, density, and location of immune cells within human colorectal tumors predict clinical outcome. Science. 2006; 313: 1960-1964.

40. Galon J, Mlecnik B, Bindea G, Angell HK, Berger A, Lagorce C, et al. Towards the introduction of the 'Immunoscore' in the classification of malignant tumours. J Pathol. 2014; 232: 199-209.

41. Pages F, Mlecnik B, Marliot F, Bindea G, Ou FS, Bifulco C, et al. International validation of the consensus Immunoscore for the classification of colon cancer: a prognostic and accuracy study. Lancet. 2018; 391: 2128-2139.

42. Mahmoud SM, Paish EC, Powe DG, Macmillan RD, Grainge MJ, Lee AH, et al. Tumor-infiltrating CD8+ lymphocytes predict clinical outcome in breast cancer. J Clin Oncol. 2011; 29: 1949-1955. 
43. Sharma P, Shen Y, Wen S, Yamada S, Jungbluth AA, Gnjatic S, et al. CD8 tumor-infiltrating lymphocytes are predictive of survival in muscle-invasive urothelial carcinoma. Proc Natl Acad Sci U S A. 2007; 104: 3967-3972.

44. Narayanan JSS, Ray P, Hayashi T, Whisenant TC, Vicente D, Carson DA, et al. Irreversible Electroporation Combined with Checkpoint Blockade and TLR7 Stimulation Induces Antitumor Immunity in a Murine Pancreatic Cancer Model. Cancer Immunol Res. 2019; 7: 1714-1726.

45. Zhao J, Wen X, Tian L, Li T, Xu C, Wen X, et al. Irreversible electroporation reverses resistance to immune checkpoint blockade in pancreatic cancer. Nat Commun. 2019; 10: 899.

\section{Figures}

A
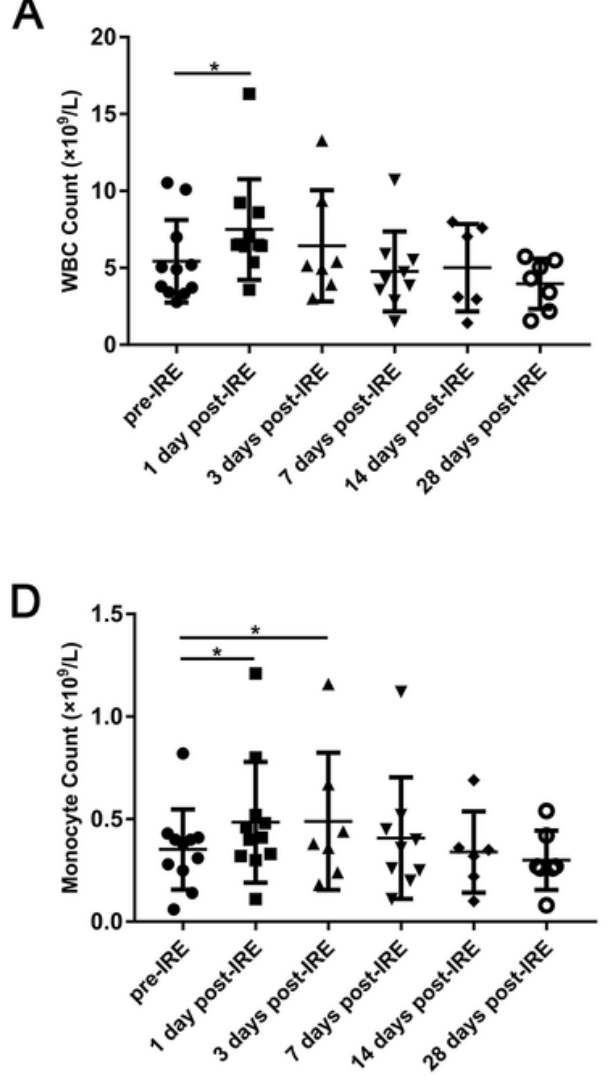

B

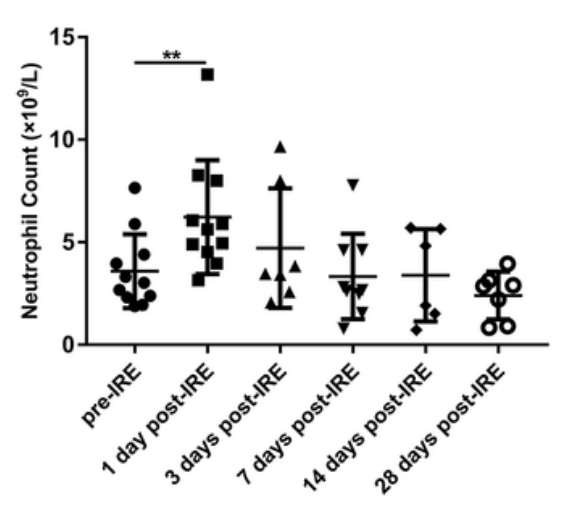

E

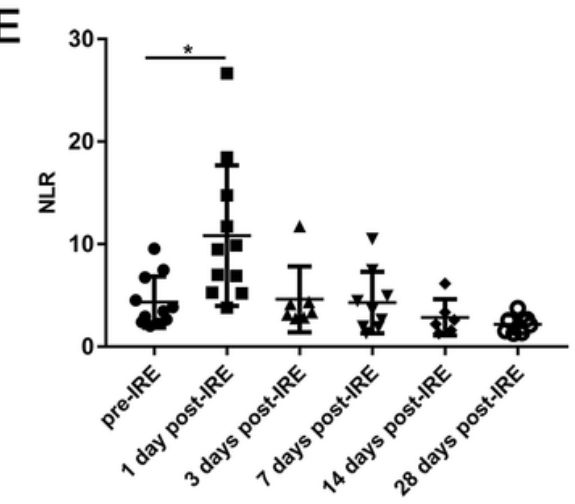

C

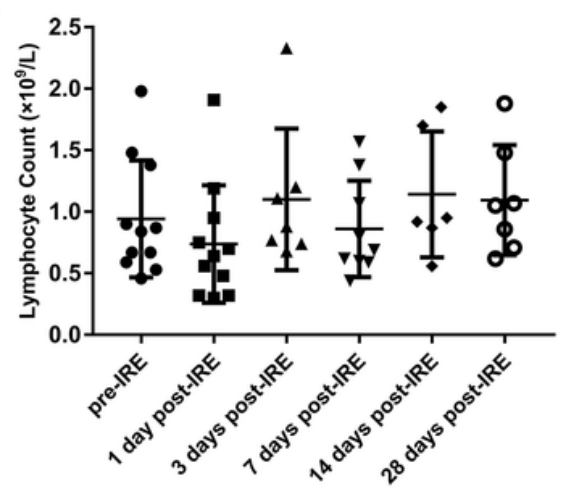

$\mathbf{F}$

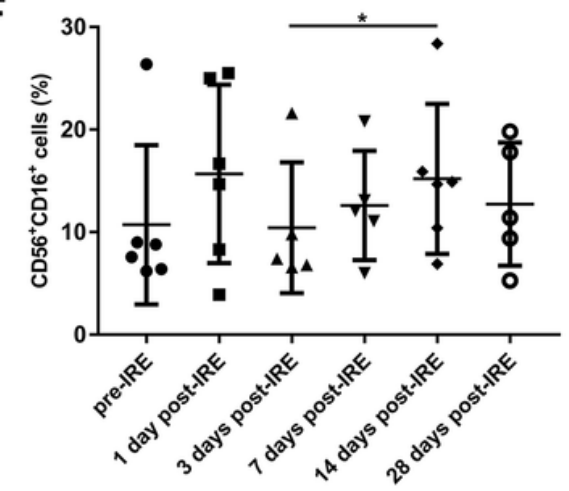

Figure 1

Immune cells in the peripheral blood of patients before IRE treatment (pre), and 1, 3, 7, 14, and 28 days post-IRE. (A-D) WBC, neutrophil, lymphocyte and monocyte counts, (E) neutrophil to lymphocyte ratio $(\mathrm{NLR}),(\mathrm{F})$ The percentage of natural killer cells $(\mathrm{CD} 56+\mathrm{CD} 16+) .{ }^{*} \mathrm{p}<0.05,{ }^{\star *} \mathrm{p}<0.01$ 
A
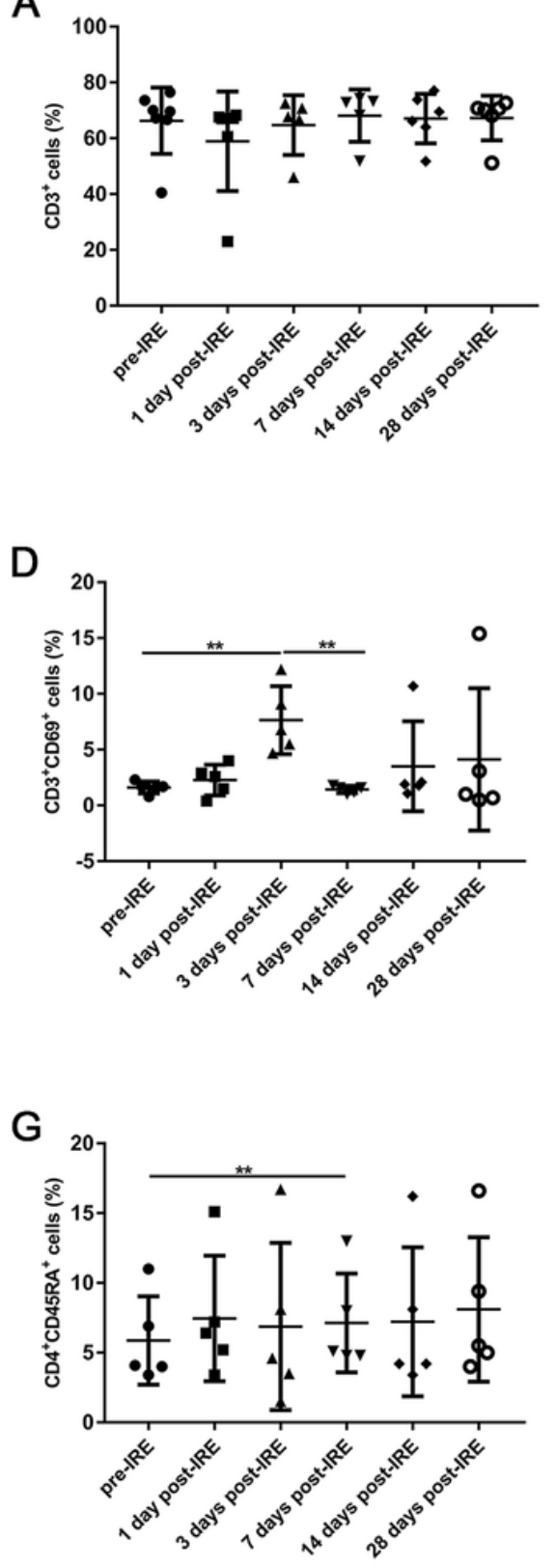

B

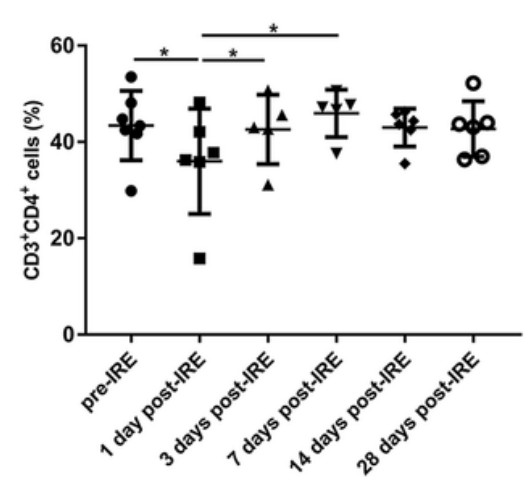

$\mathrm{E}$

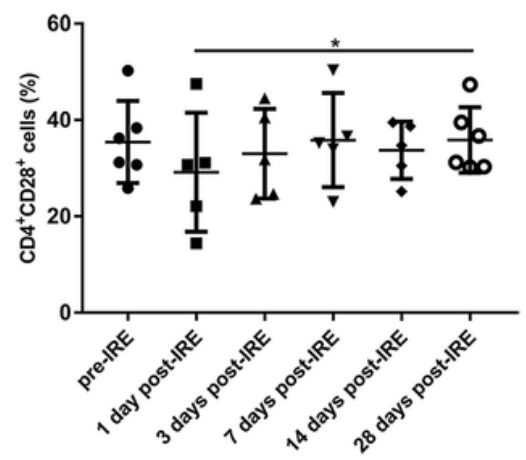

$\mathrm{H}$

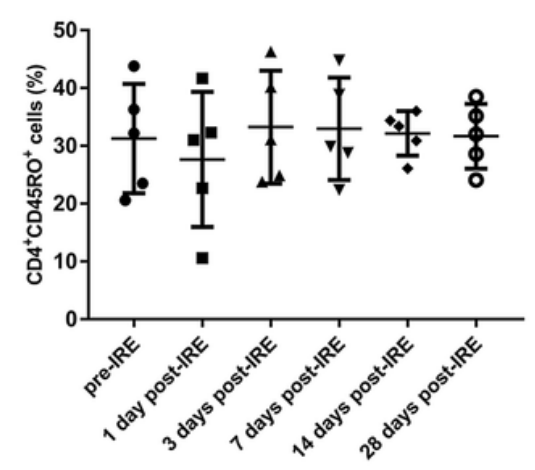

C

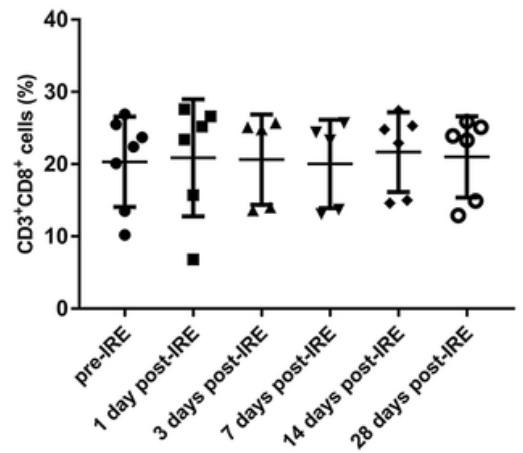

$\mathrm{F}$
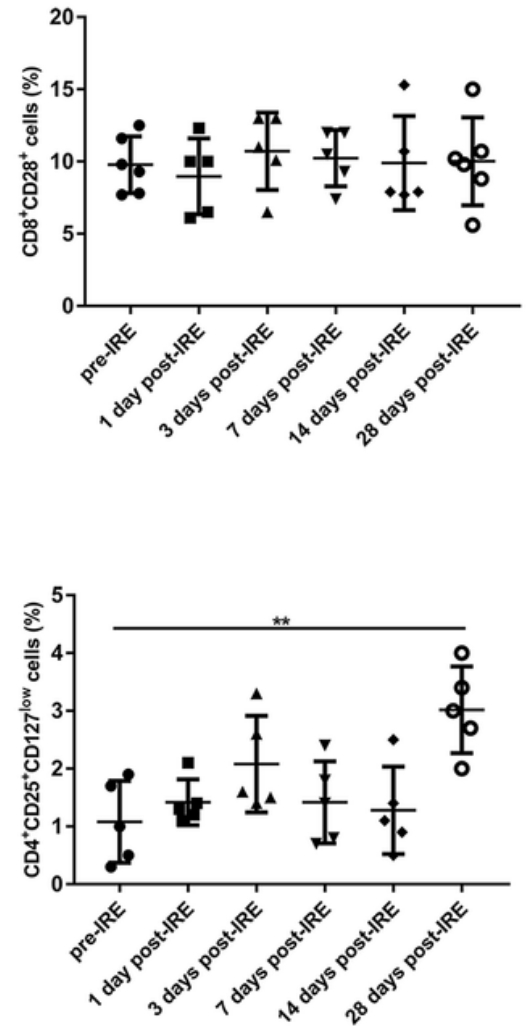

Figure 2

The percentages of immune cells in the peripheral blood of patients before IRE treatment (pre) and 1, 3, 7, 14, and 28 days post-IRE, as analyzed with flow cytometry: (A) CD3+ T cells, (B) CD3+CD4+ T cells, (C) CD3+CD8+ T cells, (D) Activated T cells (CD3+CD69+), (E) Activated CD4+ T cells (CD4+CD28+), (F) Activated CD8+ T cells (CD8+CD28+), (G) CD4+ naïve cells (CD4+CD45RA+), (H) CD4+ memory cells (CD4+CD45RO+), and (I) Regulatory T cells (CD4+CD25+CD127low). ${ }^{*} p<0.05, * * p<0.01$ 
A

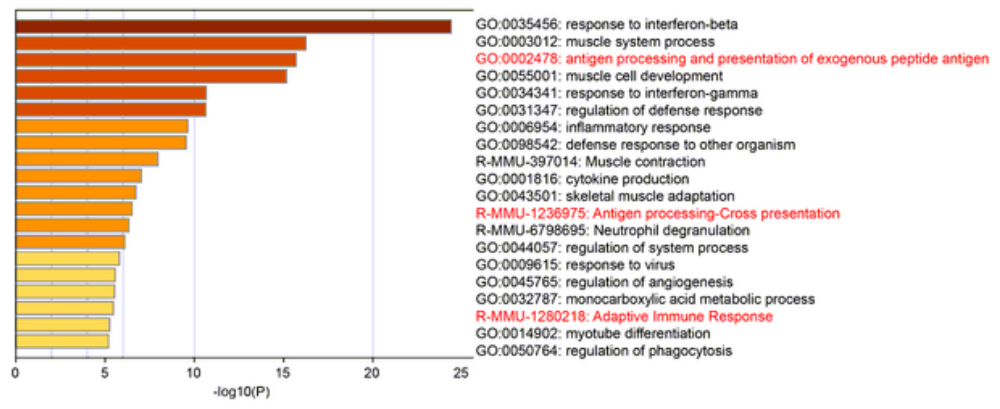

C

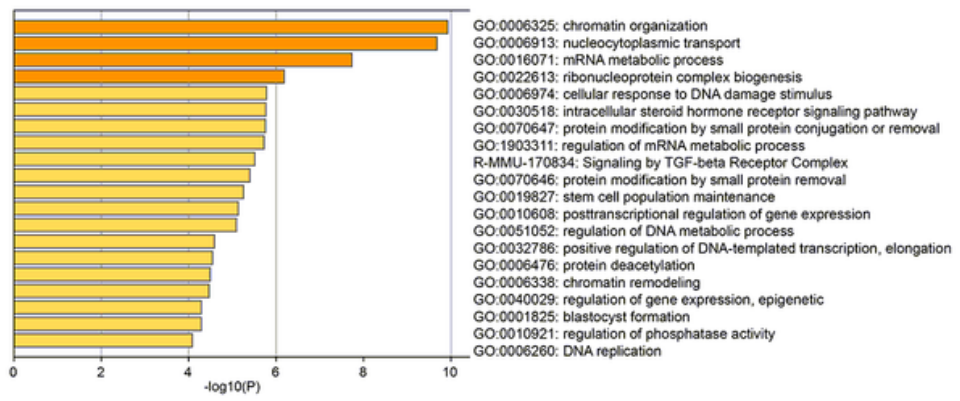

B

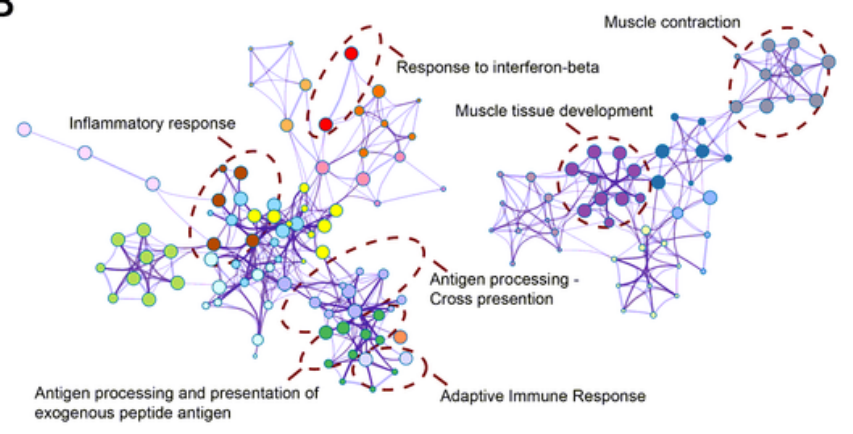

D

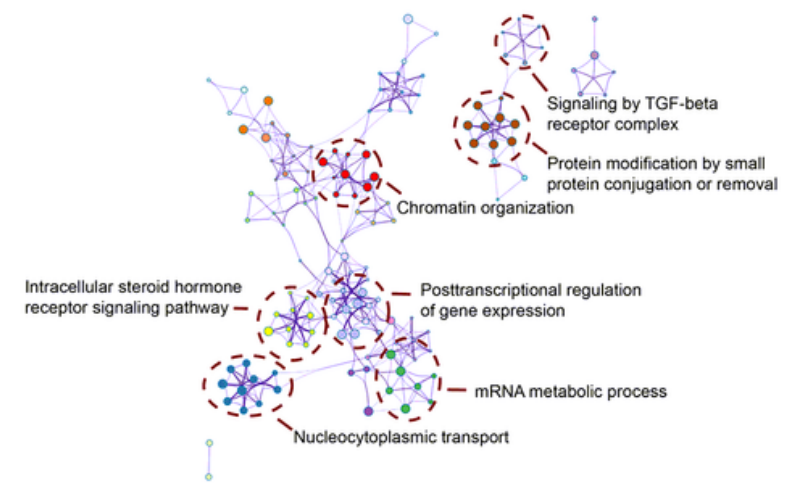

Figure 3

Gene expression profiling in the tumors of mice in the IRE and control groups 7 days post-IRE obtained from RNA sequencing. (A) Heatmap displaying enrichment of DEGs up-regulated. Adaptive immune process related pathways are highlighted in red. (B) Enriched ontology clusters of DEGs up-regulated. (C) Heatmap displaying enrichment of DEGs down-regulated. (D) Enriched ontology clusters of DEGs downregulated. 
A
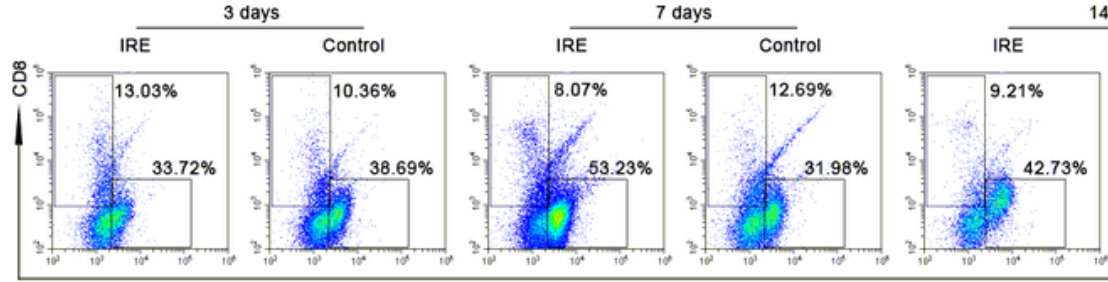

14 days

B

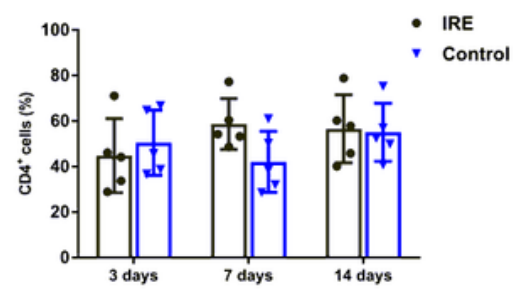

C

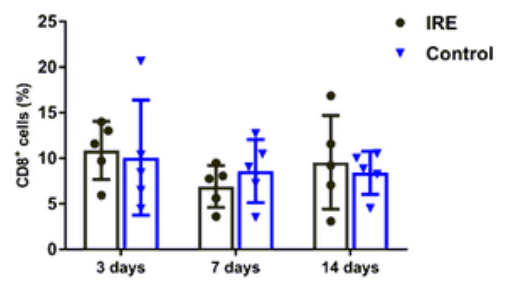

D

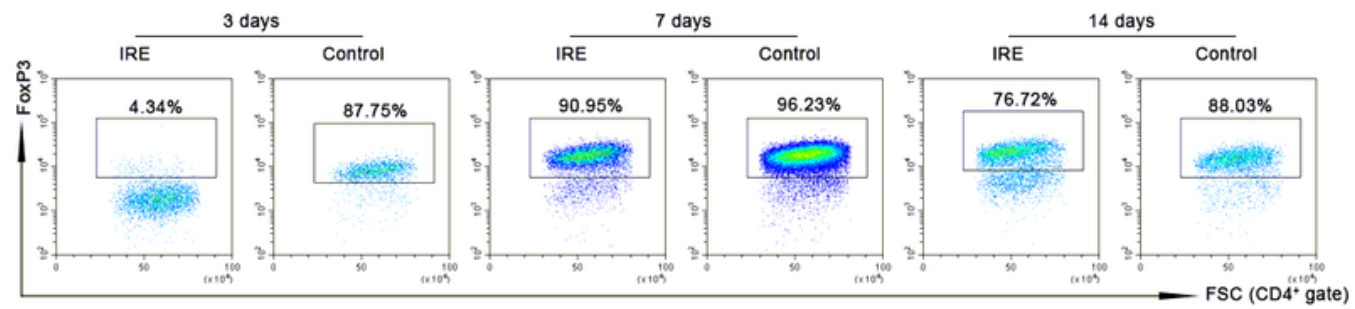

\section{$\mathrm{E}$}

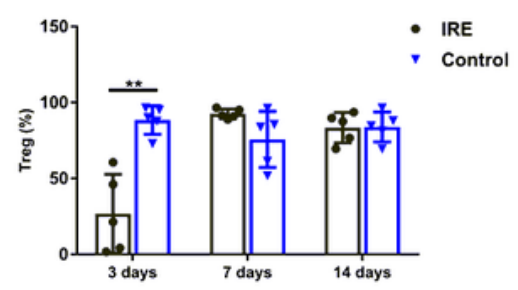

F
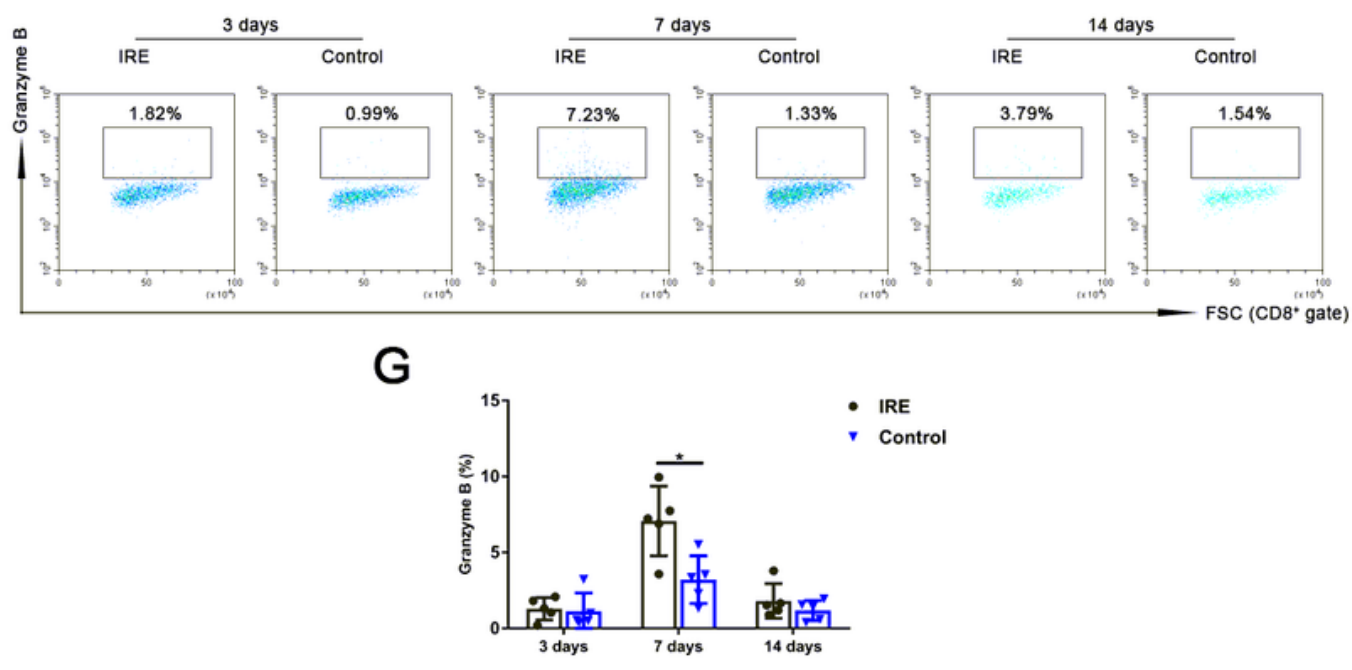

\section{Figure 4}

The percentages of tumor-infiltrating T lymphocytes of mice in the IRE and control groups 3, 7, and 14 days post-IRE, analyzed with flow cytometry. (A) Representative flow cytometry plots showing CD4+ and CD8+ $T$ cells. (B, C) The percentages of CD4+ and CD8+ T cells. (D) Representative flow cytometry plots showing regulatory $T$ cells (Treg) (CD4+FoxP3+). (E) The percentage of Treg. (F) Representative flow 
cytometry plots showing cytotoxic CD8+ T cells (CD8+Granzyme B+). (G) The percentage of cytotoxic CD8+ T cells. ${ }^{*} p<0.05,{ }^{* *} p<0.01$

A

- NS $\log 2 \mathrm{FC} \bullet P \quad P \& \log 2 \mathrm{FC}$

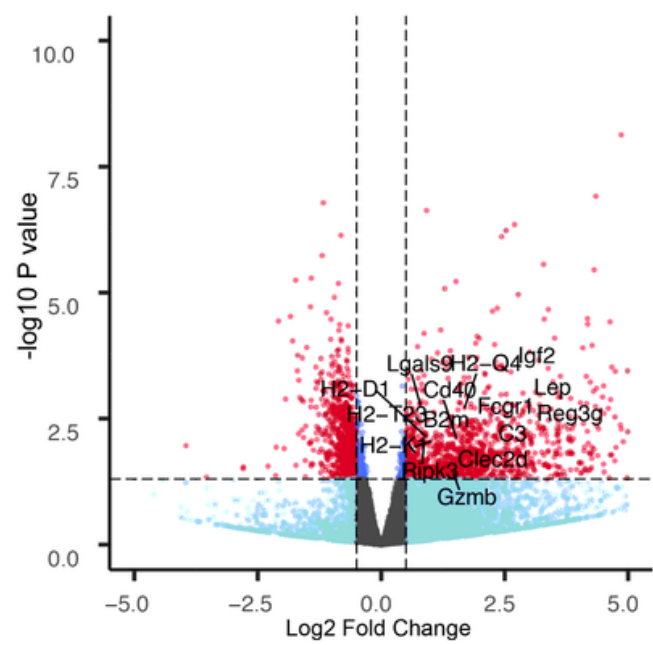

B

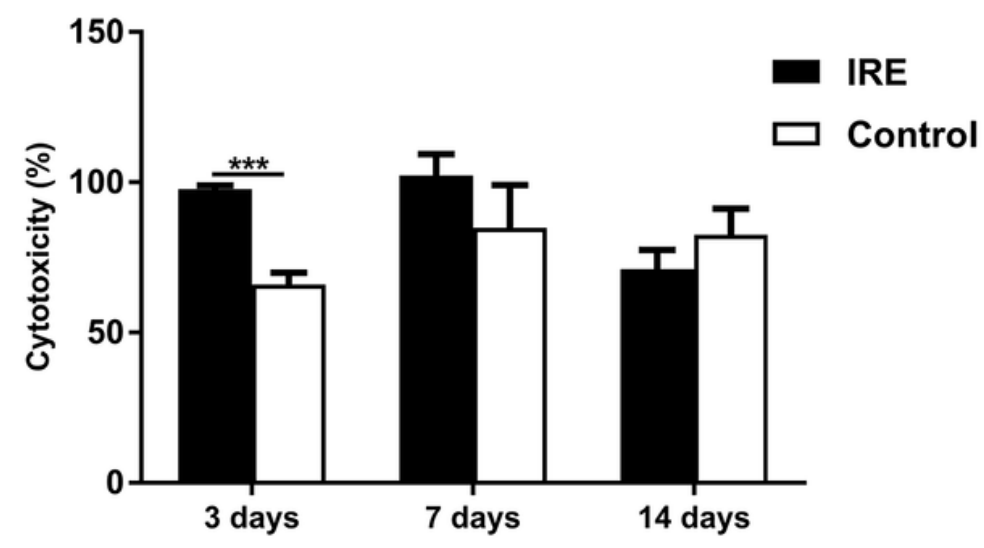

\section{Figure 5}

Cytotoxic activity of T cells from tumors of mice in the IRE and control groups. (A) Volcano plots displaying cytotoxicity associated genes, red plots represent DEGs. (B) Cytotoxicity activity of T cells were analyzed by Lactate dehydrogenase (LDH) cytotoxicity assay. 

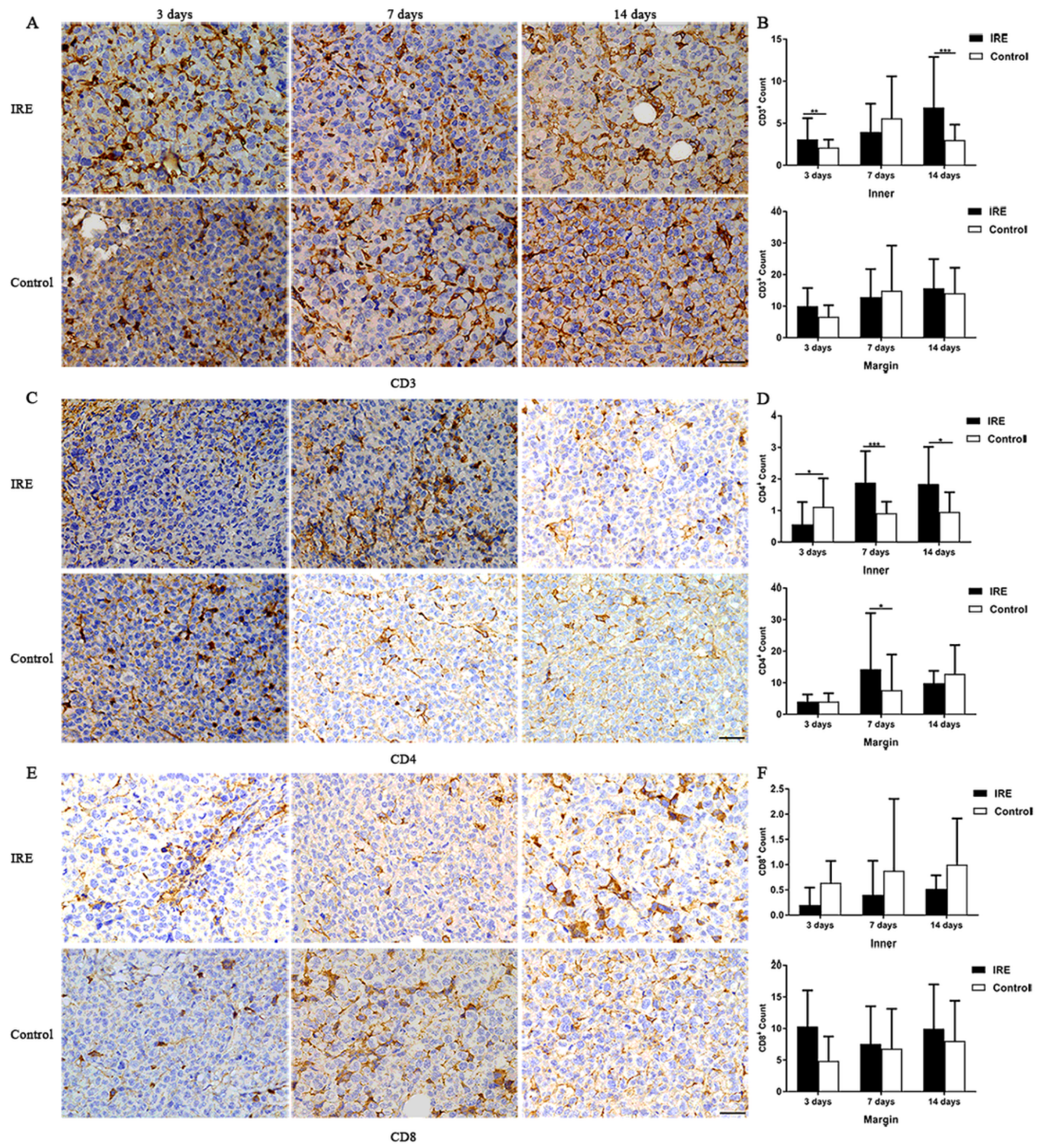

Figure 6

Tumor-infiltrating $T$ lymphocytes counts of mice in the IRE and control groups, 3, 7, and 14 days post-IRE, analyzed with immunohistochemistry. (A, C, E) Representative micrographs showing cells stained with CD3, CD4, and CD8. Scale bars $=20 \mu \mathrm{m}$. (B, D, F) The numbers of CD3+ T cells (B), CD4+ T cells (D), and CD8+ T cells $(F)$ that infiltrated into the inner regions and at the margin of tumors. ${ }^{*} p<0.05,{ }^{\star \star} p<0.01$, $\star \star \star p ~<0.001$ 

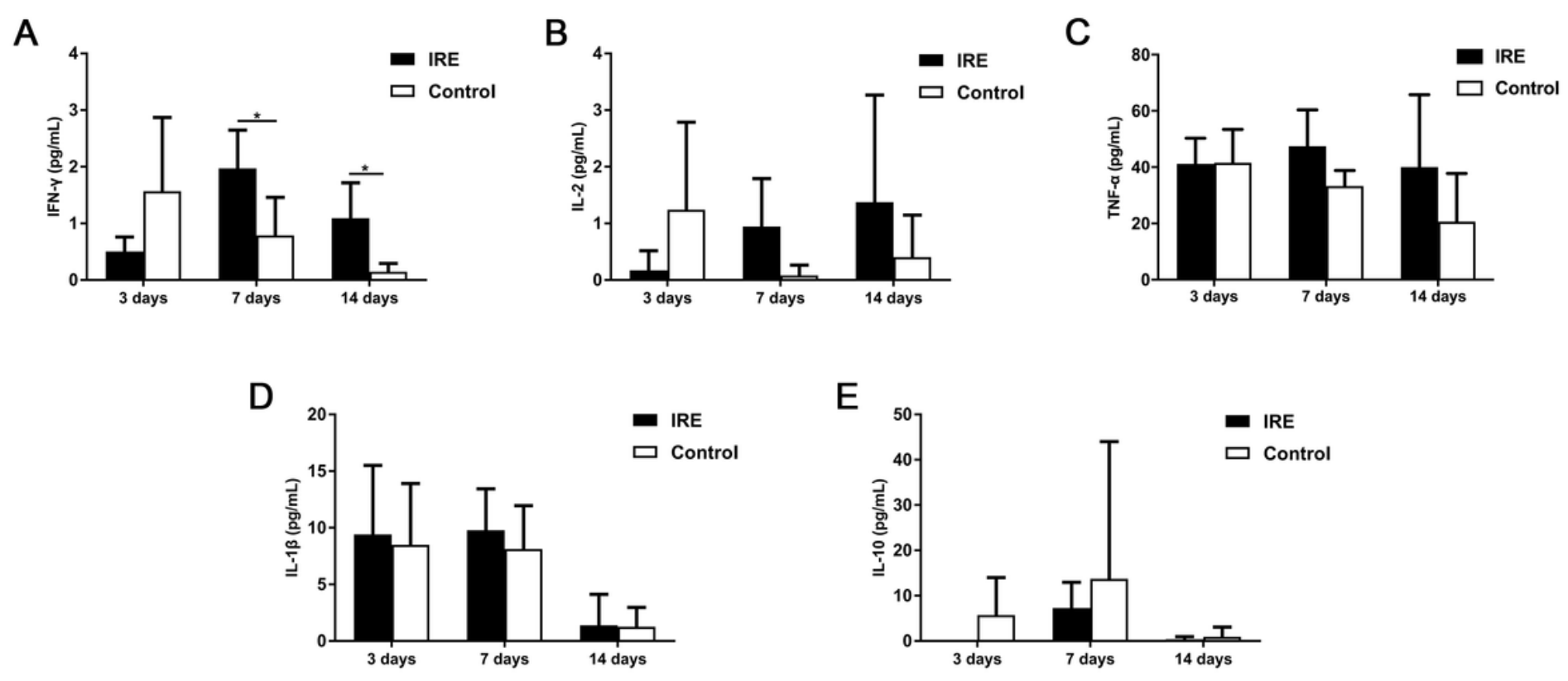

\section{Figure 7}

The concentration of serum cytokines in the mice in the IRE and control groups, 3, 7, and 14 days postIRE: (A) IFN- $\gamma$, (B) IL-2, (C) TNF-a, (D) IL-1 $\beta$, and (E) IL-10. *p $<0.05$

\section{Supplementary Files}

This is a list of supplementary files associated with this preprint. Click to download.

- AuthorChecklistFull.pdf 